
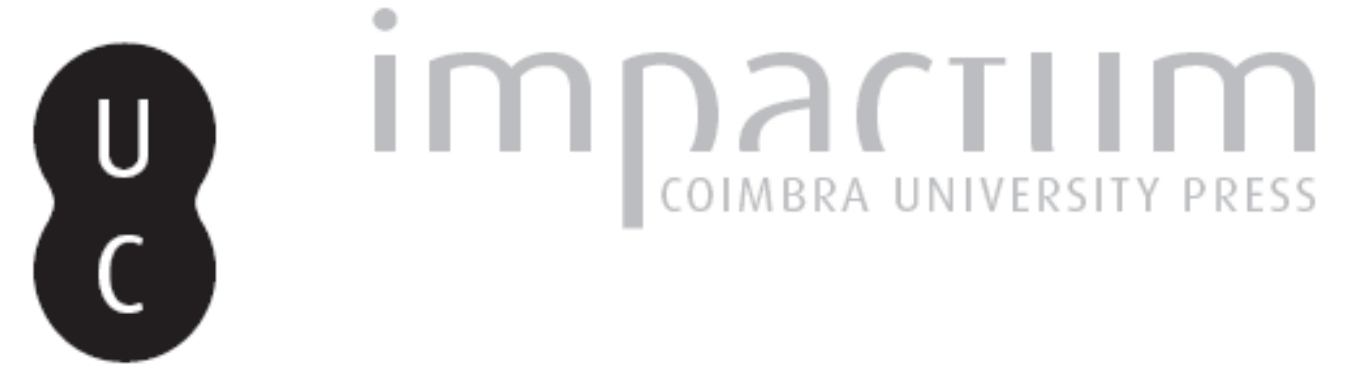

\title{
Carbonária: o exército civil do 5 de Outubro
}

\section{Autor(es): Rodrigues, Ernesto}

Publicado por: Imprensa da Universidade de Coimbra

URL persistente:

URI:http://hdl.handle.net/10316.2/42525

DOI:

DOI:https://doi.org/10.14195/0870-8584_5_12

Accessed : $\quad$ 26-Apr-2023 12:21:18

A navegação consulta e descarregamento dos títulos inseridos nas Bibliotecas Digitais UC Digitalis, UC Pombalina e UC Impactum, pressupõem a aceitação plena e sem reservas dos Termos e Condições de Uso destas Bibliotecas Digitais, disponíveis em https://digitalis.uc.pt/pt-pt/termos.

Conforme exposto nos referidos Termos e Condições de Uso, o descarregamento de títulos de acesso restrito requer uma licença válida de autorização devendo o utilizador aceder ao(s) documento(s) a partir de um endereço de IP da instituição detentora da supramencionada licença.

Ao utilizador é apenas permitido o descarregamento para uso pessoal, pelo que o emprego do(s) título(s) descarregado(s) para outro fim, designadamente comercial, carece de autorização do respetivo autor ou editor da obra.

Na medida em que todas as obras da UC Digitalis se encontram protegidas pelo Código do Direito de Autor e Direitos Conexos e demais legislação aplicável, toda a cópia, parcial ou total, deste documento, nos casos em que é legalmente admitida, deverá conter ou fazer-se acompanhar por este aviso.

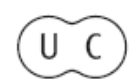




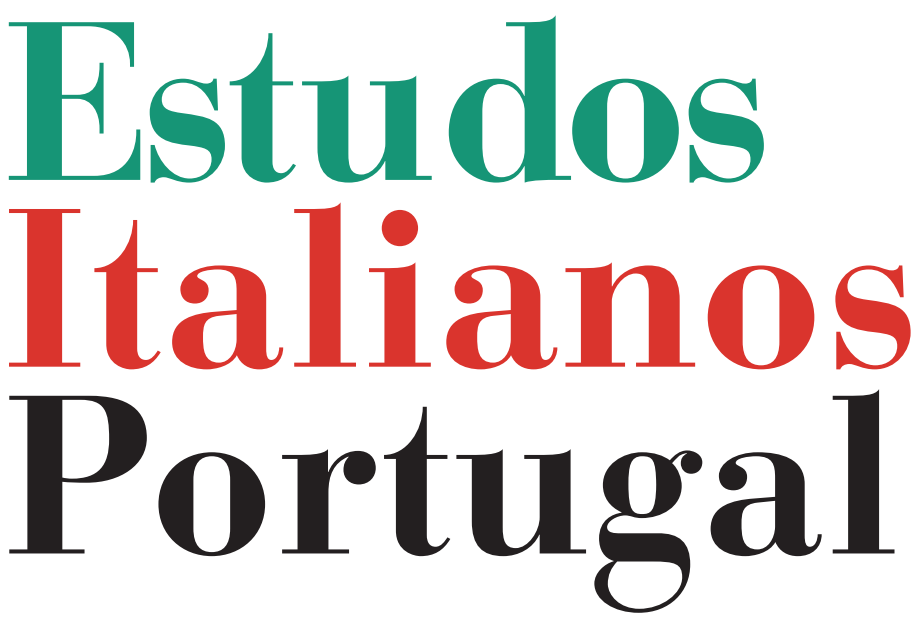

Instituto

Italiano

de Cultura

de Lisboa

Nova Série

$\mathrm{N}^{\mathbf{0}} 5$ 


\section{CARBONÁRIA, O EXÉRCITO CIVIL DO 5 DE OUTUBRO}

ERnesto Rodrigues ${ }^{\star}$

A Revolução portuguesa de 5 de Outubro de 1910 teve um protagonista inesperado: a Carbonária. O último primeiro-ministro da Monarquia, Teixeira de Sousa, confessou nunca ter ouvido falar desse exército civil. Não raros atribuem-lhe importância decisiva na viragem de regime.

Machado Santos é o herói consensual, fundador, da República. Afastado do continente no governo de "acalmação" que sucedeu ao regicídio (1908), nunca deixou de aliciar tropas para a sociedade secreta de que era triúnviro. Nas horas decisivas da Rotunda, esteve coadjuvado pelo engenheiro António Maria da Silva, um futuro primeiro-ministro repetente, agora substituindo um exilado Luz de Almeida, chefe da Alta Venda. Eram secundados pela Marinha, onde se agiganta o carbonário José Carlos da Maia ${ }^{1}$, e por centenas de civis, muitos armados, que industriavam as tropas pouco fiéis a D. Manuel II estacionadas no Rossio e se espalhavam pela cidade e arredores.

* Poeta, ficcionista, ensaísta e tradutor. Professor na Faculdade de Letras da Universidade de Lisboa.

1 Maia, Santos e o ex-primeiro-ministro António Granjo, que encabeçara a Carbonária em Chaves, são assassinados, com outros, na noite de 19 de Outubro de 1921. Rocha Martins conta o seu espanto ao saber que o "Querido José Carlos", amigo de infância, "meu irmão de estudos e de foliar", nunca lhe contara "um dos seus amores": ser filiado na Carbonária. Ver "O 19 de Outubro", Arquivo Nacional, 41, 21-10-1932, pp. 8-11 [10].

Est.Ital.Port., n.s., 5, 2010: 95-106 
Nos últimos três anos, a organização multiplicara os iniciados - o neófito, pagão, fazia-se Bom Primo -, preparara bombas, estivera em sublevações ou em golpes falhados e adiados. Provara ao Partido Republicano Português (PRP) que só com um Directório adepto da revolução armada - e não da evolução através da urna - se conseguiria derrubar Monarquia secular. A sua lista de Governo provisório, contudo, não vingou; este desacerto repetia outros, pois as dissidências pessoais corriam desde antes da vitória, e a série de desencontros afundaria a barca em 28 de Maio de 1926. Seriam receios do PRP em relação a força secreta que não controlava, nem por interposta Maçonaria, mesmo se havia elementos comuns? Seriam diferenças evidentes de classe, ou a salvaguarda de um status, face à composição heteróclita de associação hierarquizada, estanque e rigorosa? Seria uma questão de métodos?

Retratámos esse triunvirato em obra recente $^{2}$, na qual vimos Machado Santos em acção, antes e depois da dupla jornada gloriosa. Relevados os contactos com o Directório do PRP, mediados por António José de Almeida, só a figura do grão-mestre Luz de Almeida (1867-1939) exigiria um volume, enquanto sonhando uma República desde o Ultimatum (1890). Historiador privilegiado dessa sociedade secreta - visto por, entre outros, António Maria da Silva -, Luz de Almeida mais parece um herói de romance, na modéstia do porte e na firmeza da voz baixa à mesa do café, ou, sob disfarce, a palmilhar o país, iniciando e armando dezenas de milhares de patriotas, "dispostos a sacrificarem a ultima gota de sangue pelo triumpho das ideias liberaes"3, na expectativa de hora gloriosa. Assim se compreende a quase automática implantação da República nos lugares aonde chegou ordem telegrafada pelo Governo Civil de Lisboa. Importa reter o seu

2 Ernesto Rodrigues, 5 de Outubro. Uma Reconstituição, Lisboa, Gradiva, 2010.

3 Hermano Neves, Como Triumphou a Republica, Lisboa, 1910, p. 38. 
testemunho de inspiração italiana no bem sucedido quadro final; antes, fixar instantâneos, que outros alargaram já, de 1843-1853 e 1861-1862; mas, sobretudo, demorarmo-nos em associação secreta cuja primeira imagem, em Portugal, é condicionada pela propaganda miguelista.

No lapso de um século, construiu-se um imaginário negativo do carbonário (1836)/Carbonária, etimologicamente, de carbonaro (1816) e Carboneria (1820). Carbonarismo datar-se-ia de 1913, segundo Houaiss ${ }^{4}$. Em 1914, mantinham-se duas pronúncias de carbonária, uma delas com acento tónico no $i$, à italiana. Cândido de Figueiredo, que defende "Carbonaria", julgava ser a palavra "de formação portuguesa, ou composta do substantivo carbonário e do sufixo ia, que é sempre tónico", aceitando, todavia, que, "havendo no latim o adjectivo carbonárius, poderíamos dizer sociedade carbonária,

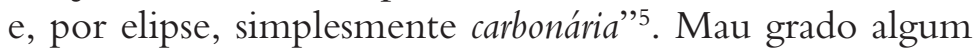
aceno de província ${ }^{6}$, com as divisões no PRP, a reacção clerical e a ditadura estadonovista, a organização vai definhando, a par dos principais mentores: Machado Santos é assassinado em 1921; Luz de Almeida morre na sua casa da Travessa da Portuguesa, em 1939; António Maria da Silva, em 1950. Lendo, todavia, deste, O Меu Depoimento, percebe-se uma existência residual no momento da escrita, entre 1943 e $1950^{7}$. Na linguagem dos nascidos nos anos 10, todavia, acusar alguém de carbonário era dizê-lo esquivo, rude, maldoso (nesta acepção, chamava-se também maçónico,

4 Dicionário Houaiss da Língua Portuguesa, Lisboa, Círculo de Leitores, 2002, p. 804.

5 O Que Se não Deve Dizer, vol. 3, 5. ${ }^{a}$ ed., Lisboa, Livraria Clássica Editora, 1955 , pp. 25-26.

6 Releve-se um periódico eborense, O Carbonário, de 27-11-1910 a 30-3-1913, 124.

7 Primeiro volume. Da Monarquia a 5 de Outubro de 1910, Lisboa, 1975, p. 189. 
republicano ou, por causa do partido de Afonso Costa, democrático), enquanto, noutros estratos, ainda depois de 1974, se começava a dizer comunista...

Secretos eram os grupos que, na passagem do século, sob D. Maria I, enxameavam os botequins lisboetas, não menos frequentados pelos moscas do intendente Pina Manique. Ausente a Corte no Brasil, a presença de Junot (1807-1808) é minada por quem, embora sorrindo ao invasor, se organiza em Conselho Conservador, congregando fidalguia, toga e sotaina $^{8}$. A subversão militar contra a regência inglesa desagua nos Mártires da Pátria (1817), maçónicos. Já o Sinédrio portuense tem melhor sorte: o 24 de Agosto de 1820 é fruto de jantares burgueses na Foz do Douro, no dia 22 de cada mês, aproveitando a ausência de Beresford no Rio de Janeiro.

Bem antes de 1913, o termo carbonarismo entra nos olhos do leitor da Gazeta de Lisboa, n. ${ }^{\circ}$ 74, 26 de Março de 1824, e n. ${ }^{\circ} 135,8$ de Junho de 1824 . Este traduz artigo de gazeta madrilena sobre as sociedades secretas espanholas até 1823, em que figuram os carbonários - donde, conviria antecipar também a datação deste vocábulo. A sua destruição, logo absorvidos por outros grupos, resultaria de terem sido encaixados entre interesses do maçonismo e dos communeros.

A contra-revolução de 1820, entretanto, vingara na Europa, e "todas as prisões de Itália e Alemanha se atulharam de suspeitos e inconfidentes", enquanto "o papa, olhando satisfeito do alto do Vaticano por sobre o Velho Mundo, cuidou ver-se nos dias bem-aventurados de Gregório VII e IX, e desenferrujou os sagrados raios com fulminar anátemas a pedreiros-livres, excomunhões a carbonários". Nesta síntese de Almeida Garrett para a década, não falta o quadro de uma

8 Ver "A Marqueza de Alorna, as Sociedades Secretas e Pina Manique" e "Junot, a Maçonaria e a revolta", Arquivo Nacional, 81, 28-7-1933, pp. 450-451, e 194, 5-1-1934, pp. 823-825. 
Itália "toda escrava - mas escrava que morde os grilhões, que tem força para os quebrar -, que os há-de espedaçar ainda", considerando que "tudo é pequeno e mesquinho no mais grandioso país da Terra" 9 . Alguns revolucionários napolitanos de 1820 refugiam-se em Portugal ${ }^{10}$.

O Terror miguelista faz emergir sociedades secretas. A Sociedade dos Divodignos deu brado, em 18 de Março de 1828. Conta Oliveira Martins:

Tinham em Coimbra os estudantes uma sociedade secreta dentre a qual foram eleitos os doze que deviam consumar a vingança bárbara de castigos ou tiranias escolares. Vinham, de Coimbra a Lisboa, três lentes, com o deão e um cónego do cabido, dar os parabéns a D. Miguel pelo seu regresso. Era de manhã, das 7 para as 8 horas, no sítio do Cartaxinho, junto a Condeixa; os doze, mascarados com lenços, a pé, armados de trabucos, ordenaram alto à comitiva que apeou. Separaram-nos, trucidando-os a tiro e a punhaladas.

Aos gritos de uma mulher, acorre povo, numeroso, por ser dia de feira: apanham nove, fogem três: "Regulavam todos entre 19 e 24 anos." Enforcados em Lisboa, "as mãos e a cabeça de três deles [são] cortadas e pregadas nos ângulos da forca", concluindo o Historiador: "Essa ferocidade anárquica, o assassinato impune, a vingança e o roubo, como na Itália Meridional, ou na Grécia, era a consequência final do movimento de decomposição lenta a que a sociedade portuguesa obedecia desde largos anos" 11 .

Nos vinte anos que sucedem, Portugal vive duas guerras civis (1832-1834 e 1846-1847). Os patuleias, derrotados

9 Portugal na Balança da Europa [1830], Lisboa, Livros Horizontes, s. d., pp. 76 e $88-89$.

${ }^{10}$ Cf. Maria Manuela Tavares Ribeiro, "Mazzini no pensamento dos utópicos portugueses", Revista de História das Ideias, 28, 2007, pp. 97-98.

11 Portugal Contemporâneo, vol. 1, Porto, Lello \& Irmão, 1981, pp. 168-169. 
na segunda, simpatizam com as revoluções nacionalistas europeias, e uma "maçonaria novíssima, [...], republicana e democrática”, emerge sobre o Mondego, na síntese apressada de Oliveira Martins:

A Carbonária italiana, dirigida pelo místico republicano Mazzini, alargando os seus ramos por toda a Europa, para fundar a república universal e redentora, infiltrara-se entre nós também com a sua alta-venda ou choça-mãe, donde dependiam as vendas ou choças filiais e as barracas. Em Coimbra havia a choça de Kossuth, o húngaro ${ }^{12}$.

É mais precisa e larga - aproveitando melhor os balanços de J. Martins de Carvalho n'O Conimbricense (1868) - Maria Manuela Tavares Ribeiro, seja a estudar "A Carbonária Lusitana em Coimbra - sua orgânica" ou "Os rituais"13. Assim, já cerca de 1843, em resposta ao governo de Costa Cabral, que facilmente suspende órgãos de Imprensa, "Há notícia da fundação de uma Alta Venda e de três Barracas, em Lisboa: Viriato, Aljubarrota e Pacheco, expedindo-se ordens e comissões para outras serem fundadas"14. Um dos redactores do jornal setembrista Opposição Nacional (Julho-Setembro de 1844), António Augusto Teixeira de Vasconcelos (1816-1878), escolhe o nome de Irmão O'Conell, ao ingressar na Loja Philadelphia, de Coimbra. Este nome não é de acaso. Romancista e grande jornalista do seu tempo, o patuleia Vasconcelos pedia outra demora; fiquemo-nos pela sua loja.

12 Cit., vol. 2, p. 381.

13 Em Portugal e a Revolução de 1848, Coimbra, Livraria Minerva, 1990, pp. $116-120$ e 120-122.

14 Cit., p. 116. Em vez de 1843, está 1834 em "Mazzini e il mazzinianesimo in Portogallo”, estratto da Nuova Antologia (Firenze, Le Monnier), 2227, luglio-settembre 2003, pp. 229-255. 
A sociedade secreta italiana Filadelfia difundira-se pela Europa e dela derivara a Carboneria, “che si sviluppò nell'Italia meridionale, [...] anche se appare oscuramente legata ai charbonniers della Franca Contea; ne furono sicuramente parte attiva un certo numero di ufficiali francesi e di gruppi dissenditi della massoneria"15. Difunde-se no centro e norte de Itália em 1814-1815, minando o exército napoleónico. Neste ano, a Maçonaria expulsa os carbonários das suas fileiras, o que não impede rápida difusão destes pelos ducados e estados da Igreja. Reforça-se em luta contra Murat e, após 1817, com a retirada do exército austríaco. Conduz as revoluções de 1820-1821 - face à revolta napolitana, Metternich elege a Carbonária como principal adversária entre as "sectes politiques"16 - e 1831, ano em que Mazzini, nela iniciado em 1827, lança a Giovine Italia. A sua composição social repetir-se-á no caso português: "Era essa diffusa tra i piccoli proprietari, nella classe dei professionisti, fra i mercanti, gli artigiani, il basso clero e soprattuto fra gli ufficiali di rango inferiore nell'esercito e nella milizia civile delle province; [...]." ${ }^{17}$

Algumas precisões na relação com Murat saem da Gazeta de Lisboa, n. ${ }^{\circ}$ 74, de 26-3-1824. Em longo artigo traduzido, temos a situação em 1815:

Os exercitos de Murat marchavão de Napoles sobre o resto da Peninsula, e este homem ambicioso, cujo throno o Carbonarismo até então havia surdamente solapado, associava dahi em diante esta Seita ás suas vistas, e della se servia como hum poderoso auxiliador. Desde então se propagou o gérmen pestilencial desta Seita demagógica pelos diversos paizes occupados pelas suas tropas: em breve porem se declarou a victoria a favor das armas Austriacas. [...]

15 Stuart J. Woolf, "La storia politica e sociale", in Storia d'Italia, vol. terzo, Dal primo Settecento all'Unità, Torino, Einaudi, 1973, p. 232.

${ }^{16}$ Ib., p. 1222.

17 Ib., p. 271. 
O Carbonarismo e o Adelfismo, erão em 1818 as duas Sociedades secretas predominantes na Italia. [...] O centro da primeira era em Napoles; o da segunda em França; [...].

Responsável pela revolução napolitana de Julho de 1820, de pouco servia proclamação imperial de Agosto, pois nesse mesmo mês a Carboneria estendia-se a Milão.

Outro artigo, sobre "Sociedades Secretas" (n. ${ }^{\circ} 180$, 2-8-1824) na Alemanha, onde, em 1819, houvera legislação contra aquelas, mostra como, desde 1821, se disseminam pelas universidades, mantendo relações com França, Itália, Suíça. Já em 4-1-1826, n. o 3, notícia datada de Roma (24-11-1825) transcreve sentença proferida contra Angelo Targhini, acusado de homicídio em 1819, e agregado à "Seita Carbonaria", que instituíra naquela cidade; e, em 13-5-1826, n. ${ }^{\circ} 137$, com data de Nápoles, 8 de Maio, noticia-se a morte do distinto magistrado Raffaeli, o qual, tendo integrado os pedreiros-livres e carbonários, veio reconhecer o perigo das "seitas perturbadoras da ordem e do socego das Nações".

A propaganda do espírito monárquico, vitorioso sobre o espírito republicano, não esmorece na oficial Gazeta de Lisboa: se o Piemonte teve os carbonários, Nápoles um Pepe e a Espanha quejandos, a Áustria a todos venceu (n. ${ }^{\circ} 248$, 19-10-1827).

Caso mais ruidoso resultou do desmantelamento, na Primavera de 1829, de uma loja de carbonários romanos fundada em 1828, com julgamento, em finais de Setembro, de 26 membros. A comissão especial nomeada por Sua Santidade decidiu-se por penas pesadas, sendo o grão-mestre sentenciado à morte.

Eis como, sob a vigência de Carlota Joaquina influindo em D. João VI ou no governo de D. Miguel, o principal diário nacional julgava atemorizar os cidadãos. Com a derrota e exílio do usurpador, não descansariam os fiéis: a sociedade “secreta, militante e política” S. Miguel de Ala (1855) será, 
quiçá, a mais operativa; impulsionada pelo clero ultramontano, decalca ritos e graus da Maçonaria e faz do exilado seu grão-mestre ${ }^{18}$.

Voltando a Coimbra. Em 1846, havia três choças da Carbonária Lusitana, com, no biénio de 1848-1850, cerca de 500 membros, obrigados a "possuir ocultamente uma arma com os competentes cartuchos". A Choça Kossuth (1853) resultava de expulsão da Alta Venda, cinco anos antes, do seu fundador - o padre António de Jesus Maria Costa -, que assim homenageava o chefe húngaro Kossuth Lajos, de passagem por Lisboa em 1852, a caminho do exílio. "Os carbonários recebiam a designação de Benigno Primo" [Bom Primo], usando "o triângulo com o vértice para baixo, símbolo da trindade - unidade, infinito, pensamento”. E, conclusão apropriada:

$\mathrm{Na}$ linha do carbonarismo italiano e do doutrinarismo mazziniano, na Carbonária Lusitânia há uma visão religiosa do mundo e da vida. O carbonário era como o apóstolo que luta pela libertação, pela unidade e, enfim, pelo ideal de fraternidade, para ser atingida, não apenas na unidade política mas também na unidade moral. Esta efectivamente só poderia atingir-se através da república. (Ribeiro, 1990, p. 120)

Em Abril de 1861, funda-se a Sociedade do Raio, "uma espécie de Carbonária"19. Tem o seu momento alto em

18 [Rocha Martins], "Uma sociedade maçónica reaccionária”, Arquivo Nacional, 19, 20-5-1932, pp. 12-13.

19 José Bruno Carreiro, Antero de Quental. Subsídios para a Sua Biografia, 2. ed., vol. 1, Ponta Delgada, Instituto Cultural, 1981, p. 168. Além do ritual de iniciação aos mais de duzentos sócios, interessa-nos a estanquicidade da organização, decisiva em tempos de repressão e denúncias: "Havia um triunvirato constituindo o governo supremo. Dividia-se em decúrias e cada decurião regia dez sócios. Cada um destes só conhecia o seu chefe e o chefe só conhecia dez subordinados. Um sócio só podia comprometer dois, o apresentante e o chefe, e este só dez". 
21-10-1862, quando aplaude, na Sala dos Capelos da Universidade, o príncipe Humberto - que viera acompanhar a irmã, Maria Pia -, "o neto de Carlos Alberto", "o filho do amigo de Garibaldi, o filho de Vítor Manuel", como abre discurso de Antero de Quental, conhecedor da Giovine Italia e demais circunscrições revolucionárias europeias ${ }^{20}$. Não nos parecem, todavia, correctas as explicações para a designação daquela Sociedade, que, segundo Luciana Stegagno Picchio ${ }^{21}$, "aurait tiré son nom des imprécations du genre 'raios te partam' prononcées par Antero et ses camarades contre leurs ennemis"... Cremos que - à luz, também, do futuro título Raios de Extinta Luz, onde se inclui "O Sol do Belo", uma espécie de hino do grupo - Antero saudava a oposição daquela Società dei Raggi, dissolvida com a revolta bolonhesa de 1802 ... Ainda em 1862, o padre António Costa - o Bom Primo Ganganelli, apelido de Clemente XIV, que abolira a Companhia de Jesus - transmitia poderes a sucessor coimbrão, com fugaz reaparecimento em $1864^{22}$. Não encontrámos acenos a I Carbonari della Montagna (1861-1862), de Giovanni Verga, que não foi traduzido.

Após vinte anos de doutrinação na rua e no quartel, aliciamento de uns 40 mil membros desde 1895-1896 (dez mil em Lisboa) e imposições ao Directório do PRP, na sequência do Ultimatum, concretiza-se objectivo maior da Carbonária. Se subsistem alguns pontos obscuros entre a bibliografia de

20 Em 1874, todavia, “a propósito de um 'manifesto' de Mazzini sobre a Reforma Intelectual, de Renan", escrevia a Oliveira Martins: "Como nos parecem hoje vagos e secos os grandes homens de há trinta anos!" (ob. cit., vol. 2, p. 28)

21 "Italie mythique d'Antero de Quental: de Garibaldi à St. François d'Assise", in Antero de Quental et l'Europe. Actes du Colloque, Paris, FCG/CCP, 1993 , p. 147.

22 [Rocha Martins], “A Carbonária e os seus juramentos”, Arquivo Nacional, 24, 24-6-1932, pp. 7-9. 
operacionais do tempo e a moderna historiografia ${ }^{23}$, interessa, agora, segundo Luz de Almeida, registar a Carbonária Italiana como servindo de "figurino" à portuguesa, e, concretamente, "a Maçonaria florestal, ou Carbonária". Esta inspiraria, desde o século XIII (quando os guelfos, partidários do Papado, se opunham à interferência dos gibelinos e Império germânico nos negócios da Itália), os lugares de iniciação (na floresta, em choças de carvoeiros), a designação dos membros e suas organizações. "Uma outra versão marca o aparecimento dos primeiros carb $\because$ no começo do século XVII"24.

Estes três pontinhos, ou triângulo com vértice para baixo, fazem parte de um simbolismo mais vasto, cujos elementos florestais e celestiais Luz de Almeida enumera, mas só parcialmente explica:

A estrela de cinco pontas, que encima o globo terrestre, representa a figura máscula de um Bom Primo, de pé, com as pernas afastadas, os braços abertos e a cabeça erguida, como que a dizer: Pronto sempre para a luta contra todas as tiranias! O termo choça é adoptado em obediência à tradição. Os primitivos carbonários italianos reuniam-se nas choças dos carvoeiros, disseminadas pelas florestas, e daí vem chamar-se também Maçonaria florestal à Carbonária. (p. 221)

23 Entre, digamos, os subsídios contidos em José [Maria] Nunes e os trabalhos de António Ventura, Anarquistas, Republicanos e Socialistas em Portugal. As Convergências Possíveis (1892-1910), Lisboa, Cosmos, 2000, e A Carbonária em Portugal. 1897-1910, 2. ${ }^{\text {a }}$ ed., Lisboa, Livros Horizonte, 2008.

${ }^{24}$ Luz de Almeida, "A obra revolucionária da propaganda/As sociedades secretas", in Luiz de Montalvor, História do Regime Republicano em Portugal, vol. 2, Lisboa, 1932, p. 214. Completar com entrevistas esclarecedoras à Imprensa, duas delas em Idalina Portugal, "Luz de Almeida. No cinquentenário da sua morte", Revista da Biblioteca Nacional, s. 2, 4 (2), 1989, pp. 141-158. Mais recente, ver Maria Estela Guedes, "Simbologia da Maçonaria Florestal num Ritual da Carbonária Portuguesa”, O Escritor, 24-25, Dezembro de 2009, pp. 228-236. 
A transformação da Maçonaria Académica em Carbonária não foi sem incidentes, dada a necessidade de incorporar o elemento popular (1897). Os vasos comunicando com a Maçonaria nem sempre eram límpidos. Interessava, em suma, subir "sempre sem dar nas vistas", fazendo "revolucionários", sim, mas, sobretudo, "atiradores" (p. 222). As carreiras de tiro regurgitavam de filiados.

Consoante a hierarquia, assim as senhas, usos de distintivos e armas entre os filiados, ou primos, que se tratam por tu. A Carbonária organiza-se em quatro graus: rachador, aspirante, mestre, mestre sublime. Integram canteiros, choças, barracas, vendas (vedetas, em localidades com um ou dois membros) e Alta Venda (até 28-1-1908, Conselho Florestal), governo supremo de cinco mestres sublimes, eleitos pela ultra-secreta Venda Jovem Portugal. A choça reúne um grupo de canteiros; a barraca compreende algumas choças; cada venda, umas tantas barracas. Inspectores percorrem o país. Um vasto serviço de informações emana dos próprios organismos e repartições do Estado: dos ministérios aos telégrafos e telefones, foi possível boicotar ou desviar qualquer serviço de informações, em 4 e 5 de Outubro, concorrendo, assim, para o êxito da Revolução. 